\title{
MU314, a novel selective estrogen receptor modulator (SERM), improves estrogen-dependent depressive behaviors
}

\author{
Izumo $N^{1}$, Ishibashi $Y^{2}$, Ono $Y^{1}$, Toho $M^{1}$, Sumino $A^{3}$, Kameyama $T^{4}$, Morikawa $T^{5}$, Shiba $Y^{5}$, Watanabe $Y^{1}$ and $M_{\text {anabe }} T^{4,5,6 *}$ \\ ${ }^{1}$ General Health Medical Center, Yokohama University of Pharmacy, 601 Matano-cho, Totsuka-ku, Yokohama-shi, Kanagawa 245-0066, Japan \\ ${ }^{2}$ Department of Biochemistry, Yokohama University of Pharmacy, 601 Matano-cho, Totsuka-ku, Yokohama-shi, Kanagawa 245-0066, Japan \\ ${ }^{3}$ Department of Pharmacology, Yokohama University of Pharmacy, 601 Matano-cho, Totsuka-ku, Yokohama-shi, Kanagawa 245-0066, Japan \\ ${ }^{4}$ Division of Gene Expression Mechanism, Institute for Comprehensive Medical Science, Fujita Health University, 1-98 Dengakugakubo, Kutsukake-cho, Toyoake, \\ Aichi 470-1192, Japan \\ ${ }^{5}$ Laboratory for Neuroanatomy and Neuropharmacology, Research Field of Professional Basic Medicine, Department of Nursing, Faculty of Nursing, Chukyogakuin \\ University, 2216 Toki-cho, Mizunami, Gifu 509-6192, Japan \\ ${ }^{6}$ Department of Child Development and Molecular Brain Science (Osaka University), United Graduate School of Child Development, Osaka University, Kanazawa \\ University, Hamamatsu University School of Medicine, Chiba University, University of Fukui, 2-2 Yamadaoka, Suita, Osaka, Japan
}

\begin{abstract}
The female hormone estrogen is involved in many vertebrate brain activities, including learning, memory, fear, anxiety, and mood. A previous study demonstrated that the voluntary activity of ovariectomized (OVX) rats, a model of estrogen deficiency and menopause, was reduced and the release of serotonin (5-HT) at the amygdala was decreased. A recent report suggested that MU314, a novel selective estrogen receptor modulator (SERM), facilitated neurite outgrowth by stimulation of the endoplasmic reticulum and its effects involved the 5-HT-related cellular system. However, the effects of MU314 on voluntary activity and/or serotonin release in OVX rats with depressive behaviors have not been clarified. In this study, 9-week-old female Wistar rats underwent OVX or sham operation. Voluntary activity and forced swimming test were monitored at 6 weeks, followed by measurements of serotonin release in the amygdala with or without MU314 administration. We found that the depressive behaviors of OVX rats analyzed by locomotor activity and forced swimming test were significantly recovered by administration of MU314. Furthermore, the suppressed serotonin release in OVX rats was recovered by MU314 treatment. This is the first report to describe the recovery effects of MU314 on estrogen-dependent depressive behaviors, suggesting the possibility that MU314 may become a new therapeutic agent.
\end{abstract}

\section{Introduction}

The female hormone estrogen performs key roles in the physiologic activities of many organs such as the reproductive system, skeletal system, cardiovascular system, and central nervous system [1,2]. In the central nervous system, it is well known that female hormones are deeply involved in learning, memory, fear, anxiety, and mood [2]. Thus, estrogen and/or its agonist treatments are effective methods for improving many psychological symptoms and diseases [3-6].

Raloxifene has been developed as a selective estrogen receptor modulator (SERM) following the synthetization of MU314 as its derivative [7,8]. The chemical structure of MU314 was previously described $[9,10]$. Although research on the effects of MU314 on bone has been performed in the past, the research focused on actual conditions and the effects on the brain were hardly examined [7-9]. Our recent in vitro study using PC12 cells demonstrated that nerve growth factor (NGF)-induced neurite outgrowth was significantly potentiated by the addition of MU314, and that these effects were mediated by not only estrogen receptors, but also the MAPK pathway and Sigma-1 [10]. Moreover, MU314 treatment increased and decreased the expression levels of tryptophan synthase (Tph) and 5-HT1a, respectively. These findings suggest the possibility that MU314 may increase serotonin release by activating the serotonin synthase $\mathrm{Tph}$, followed by
Correspondence to: Manabe T,Laboratory for Neuroanatomy and Neuropharmacology, Research Field of Professional Basic Medicine, Department of Nursing, Faculty of Nursing, Chukyogakuin University, 2216 Toki-cho, Mizunami, Gifu 509-6192, Japan, E-mail: t-manabe@chukyogakuin-u.ac.jp

Key words: Amygdala, 5-HT, Estrogen, OVX

Special Issue: Academic seeds for drugs

Katsura Takano

Associate Professor

Division of Veterinary Science

Graduate School of Life and Environmental Sciences

Osaka Prefecture University

Japan

Yasu-Taka Azuma, Ph.C., Ph.D.

Associate Professor

Principal Investigator at Laboratory on Veterinary Pharmacology

Osaka Prefecture University

Japan

Received: June 18, 2017; Accepted: July 13, 2017; Published: July 15, 2017 
downregulation of 5-HT1a receptor expression. Therefore, it is urgent to clarify the relationship between MU314 and serotonin release in the actual brain.

The estrogen deficiency model of ovariectomized (OVX) rats has been extensively utilized in the bone research field, but the involvement of estrogen in psychiatric functions is poorly understood. Our recent study demonstrated that the voluntary activity of OVX rats showed behavioral abnormalities resembling depression [11]. Furthermore, the serotonin release in the amygdala of OVX rats was decreased [11]. The amygdala expresses estrogen receptors and is a cerebral limbic system region that is highly involved in emotions [2,12-15]. Thus, estrogen and the amygdala are closely related [8]. Furthermore, the amygdala expresses 5-HT receptors (5-HT1-7) and receives serotonergic input from the raphe $[2,16-26]$. Therefore, estrogen and its moderators may be effective treatment methods for OVX-induced depressive symptoms.

In the present study, we examined the effects of MU314 on depressive behaviors and decreased serotonin release in the amygdala of OVX rats.

\section{Materials and methods}

\section{Animals and OVX operation}

The animal model used in this study was previously described with minor modifications [11,27]. In brief, the animals for the present experiments were 9-week (W)-old female Wistar rats $(\mathrm{n}=7-8)$ weighing 180-200 g. Prior to the OVX or sham operation, the rats were allowed to acclimate for at least $1 \mathrm{~W}$ to the animal maintenance facilities at our department (12-h/12-h light/dark cycle; lights on 07:00 to 19:00). All animal studies were performed in accordance with the Guiding Principles for the Care and Use of Laboratory Animals as approved by the Japanese Pharmacological Society. After $1 \mathrm{~W}$, OVX and sham operations were performed as previously described [11,28]. At $1 \mathrm{~W}$ after the operations, MU314 (100 or $300 \mu \mathrm{g} / \mathrm{kg}$ body weight; donated by Professor Ohishi) and saline $(1 \mathrm{~mL} / \mathrm{kg}$ body weight $)$ were administered (p.o. injection) five times per week for $6 \mathrm{~W}$. These procedures are schematically shown in Figure 1.

\section{Locomotor activity, forced swimming test, and microdialysis experiment}

The circadian rhythm of voluntary activity was measured using an activity sensor (model NS-AS01; Neuroscience Inc., Tokyo, Japan) at $6 \mathrm{~W}$ after the sham or OVX operation. The forced swimming test

\section{Method}

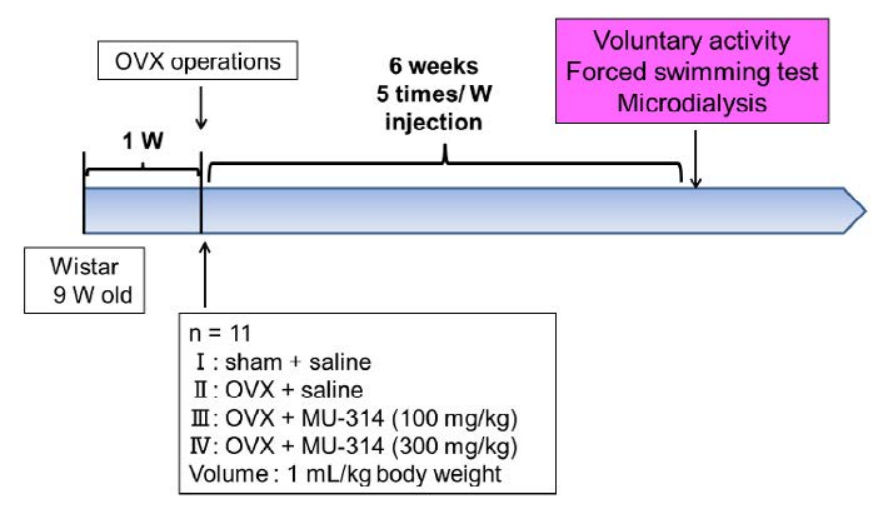

Figure 1. Schematic representation of the procedures in this study. and microdialysis experiments were carried out in accordance with previous reports [11,29].

\section{Data analysis}

All data in the study are expressed as mean \pm standard error of the mean (SEM). Statistical analyses for two-sample comparisons were performed by a two-tailed Student's t-test or one-way analysis of variance following estimation of least significant differences.

\section{Results}

\section{Spontaneous locomotor activity}

The experimental procedures in this study are shown in Figure 1. First, we examined the circadian rhythms of the locomotor activity for $15 \mathrm{~h}$ in the dark phase (17:00-08:00) in the OVX and sham-operated rats at $6 \mathrm{~W}$ postoperatively with or without MU314 treatment. The voluntary activity of OVX rats was significantly lower than that of sham-operated rats (Figure $2 \mathrm{~A}$ and $\mathrm{B}$, sham and OVX). These data closely resemble the findings of our previous reports $[11,29]$. The decreased locomotor activity in OVX rats was significantly recovered by administration of 100 and $300 \mu \mathrm{g} / \mathrm{kg}$ MU314 (Figure 2A and B, OVX and OVX-MU314).

\section{Forced swimming test}

Next, we examined the immobility time and beat counts in the forced swimming test. The beat counts and immobility time were significantly decreased and increased in OVX rats compared with those in sham-operated rats (Fig. 3A and B, sham and OVX), consistent with our previous report [29]. Treatment with MU314 significantly reversed these changes in a dose-dependent manner (Figure $3 \mathrm{~A}$ and B, OVX and OVX-MU314).

\section{Serotonin release in the amygdala}

Finally, we measured the serotonin levels in the amygdala under identical conditions. More potent decreases in the levels of serotonin release in the amygdala were observed in OVX rats compared with those in sham-operated rats (Figure $4 \mathrm{~A}$ and $\mathrm{B}$, sham and OVX), consistent with our previous studies [11,29]. These decreases in the serotonin levels in the amygdala were reversed by MU314 treatment in a dose-dependent manner (Figure 4A and B, OVX and OVX-MU314).

\section{Discussion}

Our previous study already demonstrated that the experimental conditions used in the present study did not produce any significant differences in the body weights of OVX and sham-operated rats at 2 $\mathrm{W}$, while the body weights of OVX rats at $6 \mathrm{~W}$ were significantly higher than those of sham-operated rats [11], consistent with a previous report [28]. These observations indicate that our OVX experiments were appropriate. The present study showed that the spontaneous locomotor activity in OVX rats was significantly decreased compared with that in sham-operated rats. Furthermore, the 5-HT levels in the amygdala were significantly decreased in OVX rats compared with those in sham-operated rats. These findings were consistent with our previous reports and suggested that our experimental model rats exhibited various mental processes and diseases such as fear, anxiety, depression, and schizophrenia [11,29].

In the present study, chronic administration of MU314 to OVX rats recovered the estrogen-dependent changes in their behaviors and the decreased serotonin release in their amygdala. We are the first 


\section{Voluntary activity}

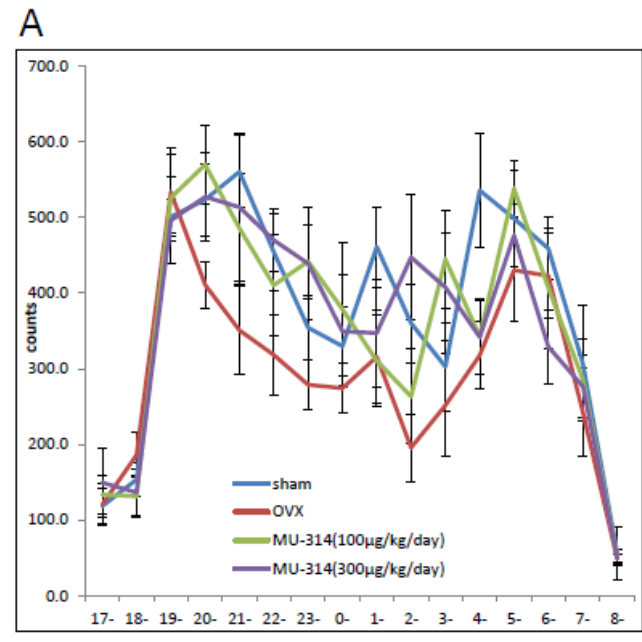

\section{B}

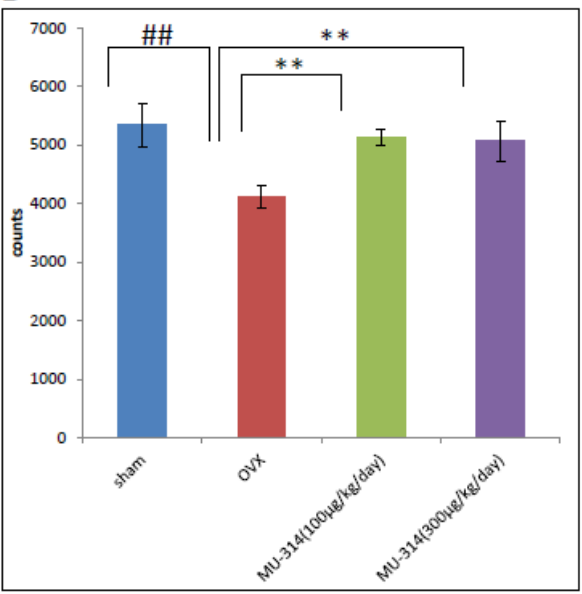

Figure 2. Circadian rhythms of voluntary activity in rats at $6 \mathrm{~W}$ after OVX or sham operation with or without MU314 treatment (17:00-08:00) (A). Data are shown as the number of counts. Summed counts over the 12-h dark phase (19:00-07:00) (B). \#\#P<0.01, ${ }^{*} \mathrm{P}<0.01$.

\section{Forced swimming test}

A

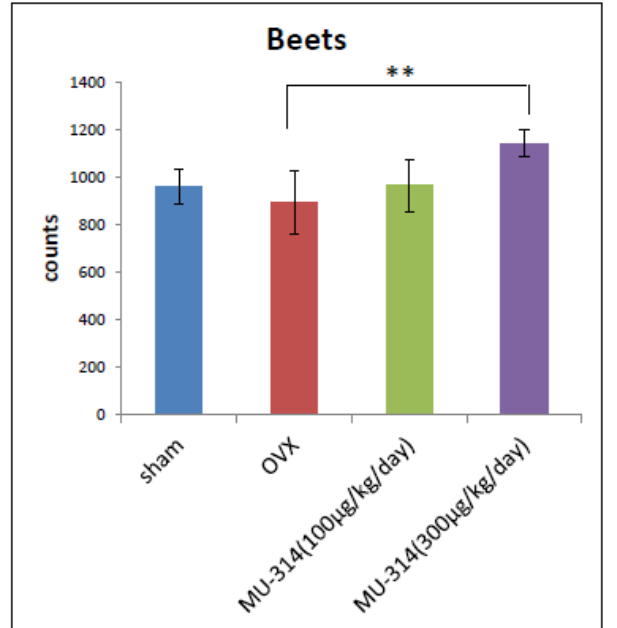

B

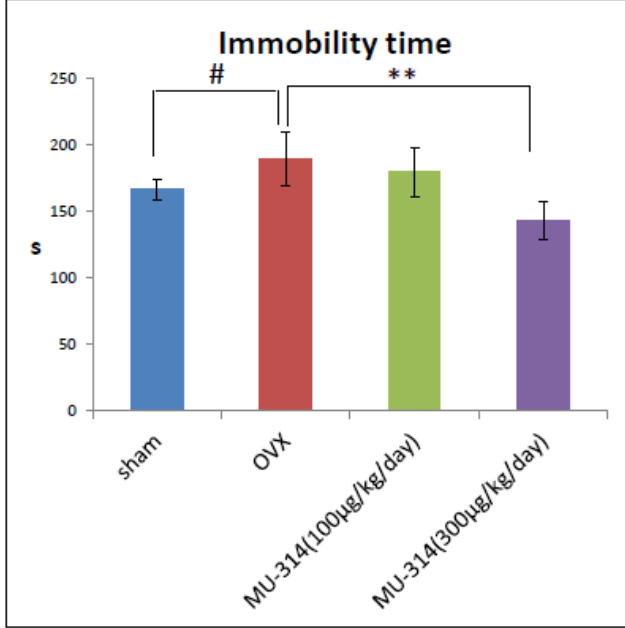

Figure 3. Beats (A) and immobility times (B) in the forced swimming test of rats at $6 \mathrm{~W}$ after OVX or sham operation with or without MU314 treatment. Data are shown as the number of counts. $\# \mathrm{P}<0.05, \# \# \mathrm{P}<0.01, * * \mathrm{P}<0.01$.

research team to show such data. Regarding spontaneous activity, the effect of MU314 was higher than that in a previous study involving treatment with the well-known anti-depression drug fluvoxamine [29]. Thus, MU314 may be a more effective therapeutic agent against estrogen-dependent depressive symptoms.

The effects of MU314 observed in the present study may affect neurite outgrowth, based on the previous finding that PC12 cells with MU314 treatment showed significantly enhanced NGF-induced neurite outgrowth in vitro [10]. In addition, estradiol treatment was reported to increase the number of dendritic spines in the amygdala $[2,30]$. Furthermore, experiments using several inhibitors revealed that the effects of MU314 were strongly related to the MAPK pathway and Sigma-1 receptor signaling in PC12 cells [10]. Both types of signals are known to be involved in neurite outgrowth induced by NGF [31-
33]. However, considering that fluvoxamine, an agonist of Sigma-1 receptor, failed to completely recover the effects of OVX [29], the effects of MU314 cannot be explained by effects on Sigma-1 receptor alone, and future research is expected.

The serotonin release in the amygdala of OVX rats was significantly increased by administration of MU314 in the present study. This may be attributed, at least in part, to the synthesis of serotonin itself, because the expression of $\mathrm{Tph}$, a serotonin synthase, was significantly elevated by MU314 treatment in PC12 cells [29]. Furthermore, as a result, serotonin receptor 5-HT1a expression was found to be downregulated in RT-PCR assays [29]. Alternatively, the reduction in voluntary activity and 5-HT and DA levels in OVX rats may result from a decreased volume of the neurons in their amygdala, because estradiol treatment of OVX rats was reported to increase the volume of the nucleus and 


\section{Microdialysis}

A

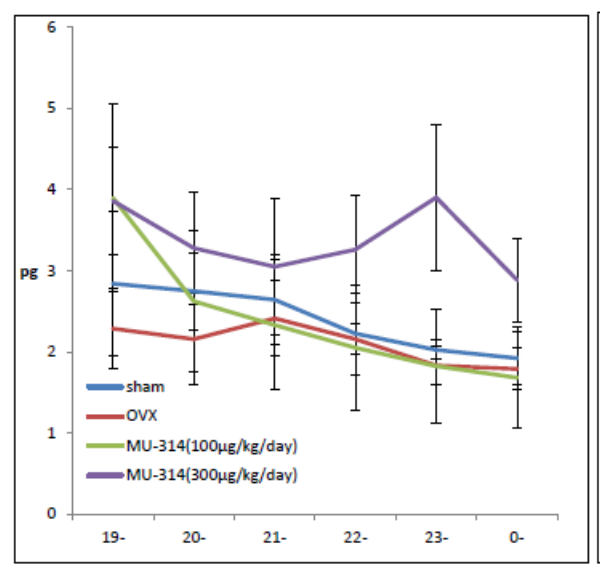

B

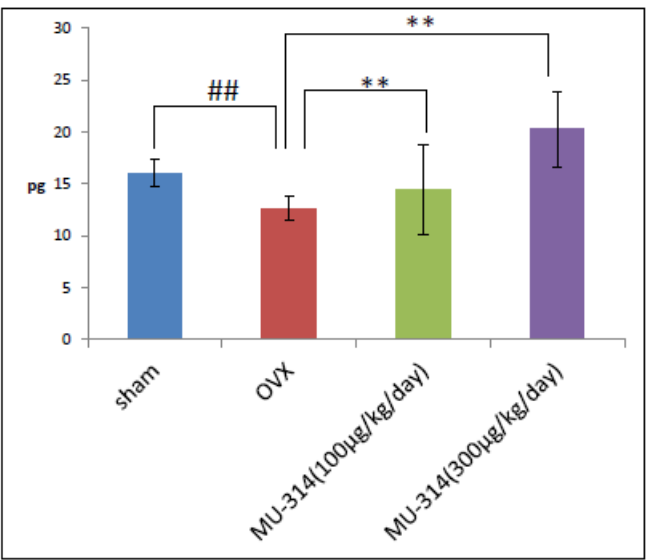

Figure 4. Circadian rhythms of the amounts of 5-HT in the amygdala at $6 \mathrm{~W}$ after OVX or sham operation with or without MU314 treatment (A). Summed levels of 5-HT over the entire 6-h dark phase (19:00-01:00) (B). \#\#P<0.01, $* * \mathrm{P}<0.01$.

cell body of the neurons in the posterodorsal medial amygdala [34]. Elucidation of the underlying molecular mechanism in vivo is desired in future studies.

In conclusion, this is the first report to describe the recovery of depression-like behaviors through elevated serotonin release induced by MU314 in vivo, suggesting the possibility that MU314 may become a new therapeutic agent.

\section{Acknowledgments}

Manabe $\mathrm{T}$ and Morikawa $\mathrm{T}$ were supported by Grants-in-Aid for Scientific Research (C) from the Ministry of Education, Culture, Sports, Science and Technology of Japan.

\section{References}

1. Sniekers YH, Weinans H, Bierma-Zeinstra SM, van Leeuwen JP, van Osch GJ (2008) Animal models for osteoarthritis: the effect of ovariectomy and estrogen treatment-a systematic approach. Osteoarthritis Cartilage 16: 533-541. [Crossref]

2. ter Horst GJ (2010) Estrogen in the limbic system. Vitam Horm82:319-338. [Crossref]

3. Craig MC, Murphy DG (2010) Estrogen therapy and Alzheimer's dementia. Ann N Y Acad Sci 1205: 245-253. [Crossref]

4. Gibbs RB (2010) Estrogen therapy and cognition: a review of the cholinergic hypothesis. Endocr Rev 31: 224-253. [Crossref]

5. Niino M, Hirotani M, Fukazawa T, Kikuchi S, Sasaki H (2009) Estrogens as potential therapeutic agents in multiple sclerosis. Cent Nerv Syst Agents Med Chem 9: 87-94. [Crossref]

6. Liu B, Xie J (2004) Increased dopamine release in vivo by estradiol benzoate from the central amygdaloid nucleus of Parkinson's disease model rats. J Neurochem 90: 654-658. [Crossref]

7. Ando Y, Ando K, Yamaguchi M, Kunitomo J, Koida M, Fukuyama R, Nakamuta H, Yamashita M, Ohta S. and Ohishi Y. 2006 A novel oxazine ring closure reaction affording (Z)-((E)-2-styrylbenzo[b]furo[3,2-d][1,3] oxazin-4-ylideno)acetaldehydes and their anti-osteoclastic bone resorption activity. BioorgMed Chem Lett 15: 58495854. [Crossref]

8. Tabuchi Y, Ando Y, Kanemura H, Kawasaki I, Ohishi T, et al. (2009) Preparation of novel (Z)-4-ylidenebenzo[b]furo[3,2-d][1,3]oxazines and their biological activity. Bioorg Med Chem 17: 3959-3967. [Crossref]

9. Fukuyama R, Shimokawa A, Kodama Y, Fujita M, Ohishi Y, et al. (2011) Antiosteoporosis effect of 5-bromo-2-(4-chlorobenzoyl)-(Z)-3-(2-cyano-3-hydroxybut2-enonyl)aminobenzo[b]furan: a novel selective estrogen receptor modulator. $J$ Pharmacol Sci 116: 214-220. [Crossref]
10. Izumo N, Ono Y, Inatomi C, Toho M, Katoh S, et al. (2017) Potentiation of nerve growth factor-induced neurite outgrowth by a novel SERM, MU314, in PC12 cells. Pharmacometrics 92: 45-52. [Crossref]

11. Izumo N, Ishibashi Y, Ohba M, Morikawa T, Manabe T (2012) Decreased voluntary activity and amygdala levels of serotonin and dopamine in ovariectomized rats. Behav Brain Res 227: 1-6. [Crossref]

12. Amunts K, Kedo O, Kindler M, Pieperhoff P, Mohlberg H, et al. (2005) Cytoarchitectonic mapping of the human amygdala, hippocampal region and entorhinal cortex: intersubject variability and probability maps. Anat Embryol 210: 343-352. [Crossref]

13. McDannald M, Kerfoot E, Gallagher M, Holland PC (2005) Amygdala central nucleus function is necessary for learning but not expression of conditioned visualorienting Behav Neurosci 119: 202-212. [Crossref]

14. Pessoa L, Adolphs R (2010) Emotion processing and the amygdala: from a 'low road' to 'many roads' of evaluating biological significance. Nat Rev Neurosci 11: 773-783. [Crossref]

15. Swanson LW, Petrovich GD (1998) What is the amygdala? Trends Neurosci 21: 323 331. [Crossref]

16. Donatti AF, Leite-Panissi CR (2009) GABAergic antagonist blocks the reduction of tonic immobility behavior induced by activation of 5-HT2 receptors in the basolateral nucleus of the amygdala in guinea pigs. Brain Res Bull 79: 358-364. [Crossref]

17. Engleman EA, Rodd ZA, Bell RL, Murphy JM (2008) The role of 5-HT3 receptors in drug abuse and as a target for pharmacotherapy. CNS Neurol Disord Drug Targets 7: 454-467. [Crossref]

18. Holmes A (2008) Genetic variation in cortico-amygdala serotonin function and risk for stress-related disease. Neurosci Biobehav Rev 32: 1293-1314. [Crossref]

19. Macedo CE, Martinez RC, Albrechet-Souza L, Molina VA, Brandão ML (2007) 5-HT2and D1-mechanisms of the basolateral nucleus of the amygdala enhance conditioned fear and impair unconditioned fear. Behav Brain Res 177: 100-108. [Crossref]

20. Reynolds GP, Mason SL, Meldrum A, De Keczer S, Parnes H, et al. (1995) 5-Hydroxytryptamine (5-HT)4 receptors in post mortem human brain tissue: distribution, pharmacology and effects of neurodegenerative diseases. Br J Pharmacol 114: 993-998. [Crossref]

21. Savitz J, Lucki I, Drevets WC (2009) 5-HT(1A) receptor function in major depressive disorder. Prog Neurobiol 88: 17-31. [Crossref]

22. Suzuki H, Han SD, Lucas LR (2010) Increased 5-HT1B receptor density in the basolateral amygdala of passive observer rats exposed to aggression. Brain Res Bull 83:38-43. [Crossref]

23. Takahashi H, Takano H, Kodaka F, Arakawa R, Yamada M, et al. (2010) Contribution of dopamine D1 and D2 receptors to amygdala activity in human. J Neurosci 30: 3043 3047. [Crossref] 
24. Tessitore A, Hariri AR, Fera F, Smith WG, Chase TN, et al. (2002) Dopamine modulates the response of the human amygdala: a study in Parkinson's disease. $J$ Neurosci 22 : 9099-9103. [Crossref]

25. van den Buuse M (2010) Modeling the positive symptoms of schizophrenia in genetically modified mice: pharmacology and methodology aspects. Schizophr Bull 36: 246-270. [Crossref]

26. Varnäs K, Thomas DR, Tupala E, Tiihonen J, Hall H (2004) Distribution of 5-HT7 receptors in the human brain: a preliminary autoradiographic study using $[3 \mathrm{H}] \mathrm{SB}-$ 269970. Neurosci Lett 367: 313-316. [Crossref]

27. Funada M, Hara C (2001) Differential effects of psychological stress on activation of the 5-hydroxytryptamine- and dopamine-containing neurons in the brain of freely moving rats. Brain Res 901: 247-251. [Crossref]

28. Fukushima T, Nitta T, Furuichi H, Izumo N, Fukuyama T, et al. (2000) Bone anabolic effects of PTH(1-34) and salmon calcitonin in ovariectomyand ovariectomy-steroidinduced osteopenic rats: a histomorphometric and biomechanical study. Jpn $J$ Pharmacol 82: 240-246. [Crossref]

29. Ishibashi Y, Izumo N, Iwata K, Morikawa T, Kamayama T, et al. (2016) Fluvoxamine reverses estrogen-dependent decline in voluntary activities and decreased amygdala levels of serotonin in ovariectomized rats. JBrain Sci 46: 5-19. [Crossref]

30. Nishizuka M, Arai Y (1982) Synapse formation in response to estrogen in the medial amygdala developing in the eye. Proc Natl Acad Sci USA 79: 7024-7026. [Crossref]

31. Hashimoto K, IshimaT (2010) A novel target of action of minocycline in NGF-induced neurite outgrowth in PC12 cells: translation initiation factor eIF4AI. PLoS One 5 e15430. [Crossref]

32. Williams TM, Ndifor AM, Near JT, Reams-Brown RR (2000) Lead enhances NGFinduced neurite outgrowth in PC12 cells by potentiating ERK/MAPK activation. Neurotoxicology 21: 1081-1089. [Crossref]

33. Ishima T, Hashimoto K (2012) Potentiation of nerve growth factor-induced neurite outgrowth in PC12 cells by ifenprodil: the role of sigma-1 and IP3 receptors. PLoS One 7: e37989. [Crossref]

34. de Castilhos J, Hermel EE, Rasia-Filho AA, Achaval M (2010) Influence of substitutive ovarian steroids in the nuclear and cell body volumes of neurons in the posterodorsal medial amygdala of adult ovariectomized female rats. Neurosci Lett 469: 19-23. [Crossref]

Copyright: (C2017 Izumo N. This is an open-access article distributed under the terms of the Creative Commons Attribution License, which permits unrestricted use, distribution, and reproduction in any medium, provided the original author and source are credited. 